\title{
MULTI RESPONSE OPTIMIZATION APPLICATION ON A MANUFACTURING FACTORY
}

\author{
Hakan Akçay ${ }^{1}$ and A. Sermet Anagün ${ }^{2}$ \\ ${ }^{1}$ Department of Industrial Engineering, Celal Bayar University, 45140, Muradiye, \\ Manisa, Turkey \\ ${ }^{2}$ Department of Industrial Engineering, Eskişehir Osmangazi University, 26480, \\ Meselik, Eskisehir, Turkey \\ hakan.akcay@cbu.edu.tr, sanagun@ogu.edu.tr
}

\begin{abstract}
The purpose of real-life problems is often to be able to find less expensive and more effective ways of production without compromising product quality because companies must provide competitive advantage to maintain existence. In order to improve quality, design of experiment techniques is employed. RSM is a widely used technique thanks to its minimum number of experiment requirement. Hence it is used especially with continuous solution spaces and high-cost experimentations. Moreover, in most cases there is more than one response that firms must optimize simultaneously. For instance companies want to reduce the costs while improving product quality. Decision making is more difficult when conflicting objectives exist. For this reason multi response optimization is an important field to study. In this study, optimization of a manufacturing problem with two responses was carried out by the application of response surface methodology (RSM) and desirability function.
\end{abstract}

Key Words- Multi-Response Optimization, Desirability Function, Response Surface Methodology, MRSM

\section{INTRODUCTION}

Customers tend to purchase quality products, timely and appropriate prices. In the face of the world's growing needs, firms must provide competitive advantages to maintain existence. Therefore, the purpose of real-life problems is often to be able to find less expensive and more effective ways of production without compromising on product quality. Companies and experts always try to achieve this goal by using statistical and mathematical optimization techniques. Optimization occurs in three different ways. Due to the nature of real life problems Nominal-the-best (N-type) is the most commonly used approach. The goal in N-type optimization is to achieve a certain target value within a predetermined specification for quality characteristic. Other types of optimizations are Smaller-the-better (S-type) and Larger-the-better (L-type). The aims of L-type and S-type approaches are to determine the optimal parameter levels to reach the greatest or smallest value of quality characteristics respectively.

In practice, the values of the parameters may be continuous as well as discrete. While the objectives and process parameters are permanent, the solution space often does not have a linear structure, so the first order models are not enough to identify the 
objective function curvatures and to create solutions. Thus second order models are needed.

Second-order models have the ability to show, how to behave the quality characteristics of interest on a surface and are capable of determining the best parameter levels. When continuous process variables exist, RSM is an effective method to use with second order models based on statistical and mathematical techniques. Because of this property RSM is widely used in real life problems. Response surface methods have been used in applications such as product quality optimization $[1 ; 3 ; 7 ; 8 ; 12]$, quality control [19], process optimization [16; 17; 18], ergonomic designs [9], structural reliability [10], and multidisciplinary design optimization problems $[4 ; 11 ; 13]$.

\section{RESPONSE SURFACE METHODOLOGY (RSM)}

Response surface methodology (RSM) is a collection of mathematical and statistical techniques that are useful for modeling and analysis in applications where a response of interest is influenced by several variables and the objective is to optimize this response [6].

RSM also has important applications in the design, development, and formulation of new products, as well as in improvement of existing product designs. RSM, first developed by Box and Wilson in 1951 has been successfully utilized in many industries for the design and improvement of systems where efficient design characteristics are sought [14]. Central Composite Design is the most widely used design technique in second order response surface models, thanks to provide scanning experimental region by a minimum number of experiments and rotatibility feature. In general, Response surface method consists of three phases [15];

Phase 1. Development of an experimental framework

Phase 2. Create response functions - predict the parameters of the functions

Phase 3. Optimization

In the first phase, feature of the objective function to be used is determined and the appropriate experimental design is prepared which provides the ability to retain information necessary for the optimization of the problem and modeling of the objective function. In the second phase, response function which best expresses the data obtained from applied design is generated and the objective function coefficients are predicted. In the last phase, optimum parameter levels determined to obtain the optimal value of the objective function are created in the light of the experiment results.

\section{DESIRABILITY FUNCTION}

Problems in multi response form have more than one response to a given situation. There are various techniques to optimize multi response problems. One of the most used methods to solve multi response surface problems is the desirability function. Because, optimization of all responses simultaneously is possible by combining them into a single objective function, which basically represents the relationship of all responses that are to be optimized [5]. 
A desirability function, $\mathrm{D}(\mathrm{Y})$, is typically a (weighted) geometric mean of $\mathrm{n}$ individual desirability functions, $d_{i}\left(y_{i}\right)$, one for each element, $y_{i}$ of $Y$. Each $d_{i}\left(y_{i}\right)$ value is converted from associated response $y_{i}$ and scaled to be between 0 and 1 . With a value of zero indicating unacceptable quality and 1 point out that the quality of associated response is optimal. A general form of mathematical relationship of responses with desirability function is as follows;

$\max D(Y)=\left(d_{1}\left(y_{1}\right)^{k_{1}} \times d_{2}\left(y_{2}\right)^{k_{2}} \times \ldots \times d_{n}\left(y_{n}\right)^{k_{n}}\right)^{\frac{1}{\sum_{i} k_{i}}}$

$y_{i}$ denote the determined value of response $i, d_{i}\left(y_{i}\right)$ is the converted desirability value of $i$ 'th response and $k_{i}$ represent the relative importance of response $i$ compared to others. If all responses have the same importance, then $\mathrm{D}(\mathrm{Y})$ become a geometric mean of all $\mathrm{n}$ transformed responses without weights. Overall desirability value can only be close to 1 if all of the responses are close to their optimal values, because $D(Y)$ is a geometric mean of the $d_{i}\left(y_{i}\right)^{\prime}$ s. Likewise, $D(Y)$ will be small if any of the $d_{i}\left(y_{i}\right)^{\prime}$ s are sufficiently close to zero. In consequence, to optimize responses simultaneously, one seeks to find values of $x$ to maximize $D(Y)[2]$.

While optimization occurs in three different ways, desirability functions can be determined for any three kinds of questions. Aksezer stated that, weighted linear transformations are flexible in determining the risk associated with deviations from desired response levels. Because of the responses that optimized in this problem are Ltype, a larger-the-better desirability function and transformation from Aksezer's study are as follows [5]:

If the response of interest is a kind of maximization problem, then the proposed individual larger-the-better desirability function is

$d_{i}\left(y_{i}\right)=\left\{\begin{array}{cc}0 & y_{i}<L S L \\ \left(\frac{y_{i}-L S L}{U S L-L S L}\right)^{S} & L S L \leq y_{i} \leq U S L \\ 1 & y_{i}>U S L\end{array}\right.$

where LSL and USL are the lower and upper specification limits of the associated response $y_{i}$. The weight exponent s specifies the form of the response within the range of interest. With this desirability function USL automatically becomes the desired maximum value. It is the practical upper bound which any value above this would not improve the response. 


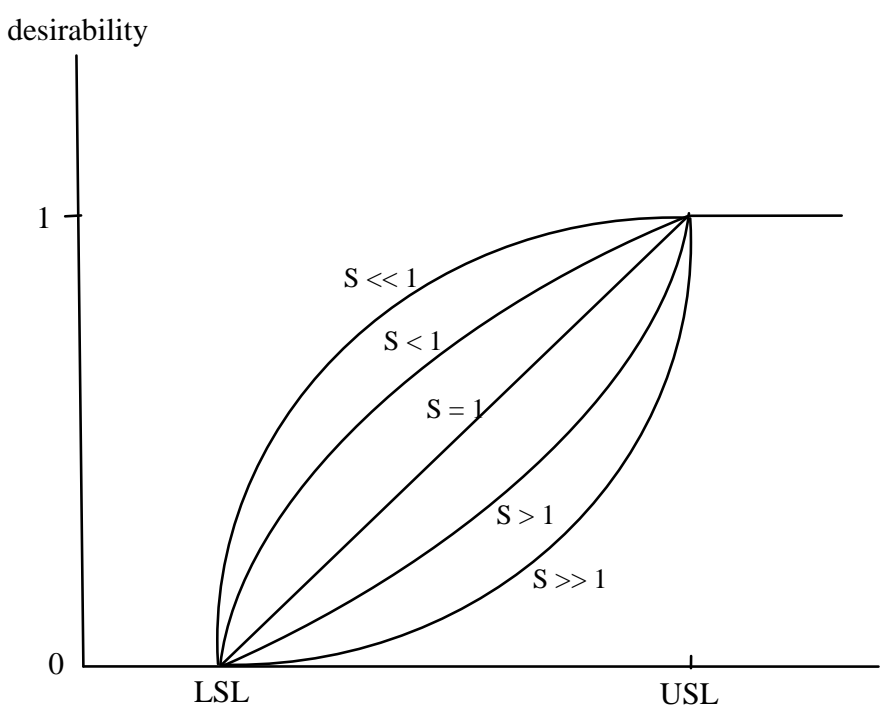

Figure 1. Larger-The-Better Desirability Function

It can clearly be observed from the shape of individual desirability function for various settings of its corresponding parameters. For example; for user specified value $s=1$ the desirability function increases linearly, for $s<1$ the function is convex, and for $s>1$ the function is concave. Note that weight $s$ provide greater flexibility in assigning the individual desirability within the range of interest. While these weight coefficient denote the desired trend of the response within itself, importance coefficient of each response, $\mathrm{k}_{\mathrm{i}}{ }^{\prime} \mathrm{s}$, associates the priority sequence of all responses so that a comparison between them is possible [5].

\section{A CASE STUDY ON A MANUFACTURING FACTORY}

\subsection{Development of Experimental Framework}

There are two responses in the problem. A central composite design application is carried out by taking three factors into account which affect responses. The design consists of a total of 20 experiments of which 6 center points, 8 factorial points, and 6 axial points. Design matrix and experimental results are given in Table 1. Zeros indicate center points, -1 and 1 specify factorial points, $-1,6818$ and 1,6818 state axial points. Real values of the design factors are not given due to the principle of company information security. Therefore, the design matrix is expressed in encoded values. 
Table 1. Design matrix and values of quality characteristics

\begin{tabular}{|c|c|c|c|c|c|c|c|}
\hline $\begin{array}{l}\text { Std } \\
\text { Order }\end{array}$ & A & B & C & $\begin{array}{c}\text { Response 1 } \\
\text { Run 1 }\end{array}$ & $\begin{array}{c}\text { Response 1 } \\
\text { Run 2 }\end{array}$ & $\begin{array}{c}\text { Response 2 } \\
\text { Run 1 }\end{array}$ & $\begin{array}{c}\text { Response 2 } \\
\text { Run 2 }\end{array}$ \\
\hline 1 & -1 & -1 & -1 & 205,577 & 206,251 & 109,611 & 111,017 \\
\hline 2 & 1 & -1 & -1 & 201,066 & 197,119 & 104,875 & 111,415 \\
\hline 3 & -1 & 1 & -1 & 210,313 & 208,396 & 118,438 & 118,150 \\
\hline 4 & 1 & 1 & -1 & 200,728 & 203,660 & 120,211 & 117,166 \\
\hline 5 & -1 & -1 & 1 & 198,134 & 196,330 & 110,400 & 112,681 \\
\hline 6 & 1 & -1 & 1 & 193,285 & 197,232 & 105,047 & 104,138 \\
\hline 7 & -1 & 1 & 1 & 198,134 & 201,630 & 107,581 & 108,709 \\
\hline 8 & 1 & 1 & 1 & 199,938 & 202,419 & 109,385 & 113,332 \\
\hline 9 & $-1,6818$ & 0 & 0 & 202,645 & 205,238 & 106,115 & 114,460 \\
\hline 10 & 1,6818 & 0 & 0 & 201,517 & 201,179 & 112,317 & 114,911 \\
\hline 11 & 0 & $-1,6818$ & 0 & 199,036 & 202,870 & 106,453 & 108,709 \\
\hline 12 & 0 & 1,6818 & 0 & 203,321 & 203,209 & 115,588 & 110,626 \\
\hline 13 & 0 & 0 & $-1,6818$ & 201,292 & 201,630 & 112,543 & 115,926 \\
\hline 14 & 0 & 0 & 1,6818 & 197,457 & 195,621 & 98,334 & 102,324 \\
\hline 15 & 0 & 0 & 0 & 188,925 & 191,668 & 105,036 & 106,341 \\
\hline 16 & 0 & 0 & 0 & 189,653 & 190,074 & 108,483 & 104,049 \\
\hline 17 & 0 & 0 & 0 & 193,172 & 186,068 & 105,777 & 109,273 \\
\hline 18 & 0 & 0 & 0 & 187,647 & 189,730 & 107,130 & 105,438 \\
\hline 19 & 0 & 0 & 0 & 190,127 & 186,444 & 106,994 & 103,995 \\
\hline 20 & 0 & 0 & 0 & 188,436 & 189,789 & 104,536 & 106,115 \\
\hline
\end{tabular}

\subsection{Create Response Functions - Predict the parameters of the functions}

Using the response data in Table 1, prediction functions for each response were generated via Design-Expert (www.statease.com). Table 2 and Table 3 show ANOVA analyses for both responses. Since the model p values are less than 0.05 , both models suggested are significant according to a 95\% confidence interval. Equation (3) and equation (4) are the quadratic surface functions for the Response 1 and Response 2, respectively.

Table 2. ANOVA Results for Response 1

\begin{tabular}{l|rrrrrl}
\hline Source & \multicolumn{1}{l}{$\begin{array}{l}\text { Sum of } \\
\text { Squares }\end{array}$} & df & Mean Square & F Value & $\begin{array}{l}\boldsymbol{p} \text {-value } \\
\text { Prob }>\boldsymbol{F}\end{array}$ & Statement \\
\hline Model & 1520,0993 & 7 & 217,1570 & 53,5151 & $<0.0001$ & significant \\
A & 52,9826 & 1 & 52,9826 & 13,0568 & 0.0010 & \\
B & 52,8689 & 1 & 52,8689 & 13,0288 & 0.0010 & \\
C & 143,3053 & 1 & 143,3053 & 35,3155 & $<0.0001$ & \\
AB & 2,1477 & 1 & 2,1477 & 0,5086 & 0.4812 & \\
AC & 44,2558 & 1 & 44,2558 & 10,4809 & 0.0029 & \\
BC & 1,0282 & 1 & 1,0282 & 0,2435 & 0.6253 & \\
$\mathrm{~A}^{2}$ & 600,3382 & 1 & 600,3382 & 147,9445 & $<0.0001$ & \\
$\mathrm{~B}^{2}$ & 551,5400 & 1 & 551,5400 & 135,9189 & $<0.0001$ & \\
$\mathrm{C}^{2}$ & 309,1852 & 1 & 309,1852 & 76,1941 & $<0.0001$ & \\
\hline Residual & 129,8516 & 32 & 4,0579 & & & \\
Lack of Fit & 39,9243 & 7 & 5,7035 & 1,5856 & 0.1858 & not significant \\
Pure Error & 89,9272 & 25 & 3,5971 & & & \\
Cor Total & 1649,9508 & 39 & & & & \\
\hline
\end{tabular}


Table 3. ANOVA Results for Response 2

\begin{tabular}{l|rrrrrr}
\hline Source & \multicolumn{1}{l}{$\begin{array}{l}\text { Sum of } \\
\text { Squares }\end{array}$} & $\boldsymbol{d} \boldsymbol{f}$ & Mean Square & $\boldsymbol{F}$ Value & $\begin{array}{l}\boldsymbol{p} \text {-value } \\
\text { Prob }>\boldsymbol{F}\end{array}$ & Statement \\
\hline Model & 745,0482 & 9 & 82,7831 & 12,0770 & $<0.0001$ & significant \\
$\mathrm{A}$ & 0,0011 & 1 & 0,0011 & 0,0002 & 0.9901 & \\
$\mathrm{~B}$ & 142,4436 & 1 & 142,4436 & 20,7807 & $<0.0001$ & \\
$\mathrm{C}$ & 273,1928 & 1 & 273,1928 & 39,8554 & $<0.0001$ & \\
$\mathrm{AB}$ & 40,4814 & 1 & 40,4814 & 5,9057 & 0.0213 & \\
$\mathrm{AC}$ & 0,9604 & 1 & 0,9604 & 0,1401 & 0.7108 & \\
$\mathrm{BC}$ & 57,4034 & 1 & 57,4034 & 8,3744 & 0.0070 & \\
$\mathrm{~A}^{2}$ & 158,2770 & 1 & 158,2770 & 23,0906 & $<0.0001$ & \\
$\mathrm{~B}^{2}$ & 90,8405 & 1 & 90,8405 & 13,2525 & 0.0010 & \\
$\mathrm{C}^{2}$ & 13,8276 & 1 & 13,8276 & 2,0173 & 0.1658 & \\
\hline Residual & 205,6381 & 30 & 6,8546 & & & \\
Lack of Fit & 70,0010 & 5 & 14,0002 & 2,5805 & 0.0515 & not significant \\
Pure Error & 135,6371 & 25 & 5,4255 & & & \\
Cor Total & 950,6863 & 39 & & & & \\
\hline
\end{tabular}

$f_{1}(x)=9582,91581-24,08191 * A-2,32636 * B-1,19363 * C+0,0014546 * A C+$

$0,017069 * A^{2}+0,0015275 * B^{2}+0,000643318 * C^{2}$

$f_{2}(x)=5497,98285-13,2668 * A-2,07842 * B-0,33764 * C+0,00181776 * A B-$

$0,000496055 * B C+0,00850717 * A^{2}+0,000595901 * B^{2}$

\subsection{Optimization}

Firstly responses are optimized individually. Maximum value for Response 1 is calculated 237,117. In this case, factors A and C stay at their minimum level, while factor B sets at maximum level. Maximization for Response 2 has resulted in 136,909. In this instance, factors $A$ and $B$ set at their maximum level and C minimum level (Figure 2). Maximum value of overall desirability function for this two responses obtained was 0,87 . As a result of interviews with company officials, it is understood that simultaneous optimization results provide the requirements. Therefore, the best parameter levels are determined for the process parameters as coded values. In this case factors $A$ and $C$ set at their minimum level $(-1,6818)$ while factor B stays maximum level $(1,6818)$ whereas Response 1 and Response 2 get the values of 237 and 127 respectively. 


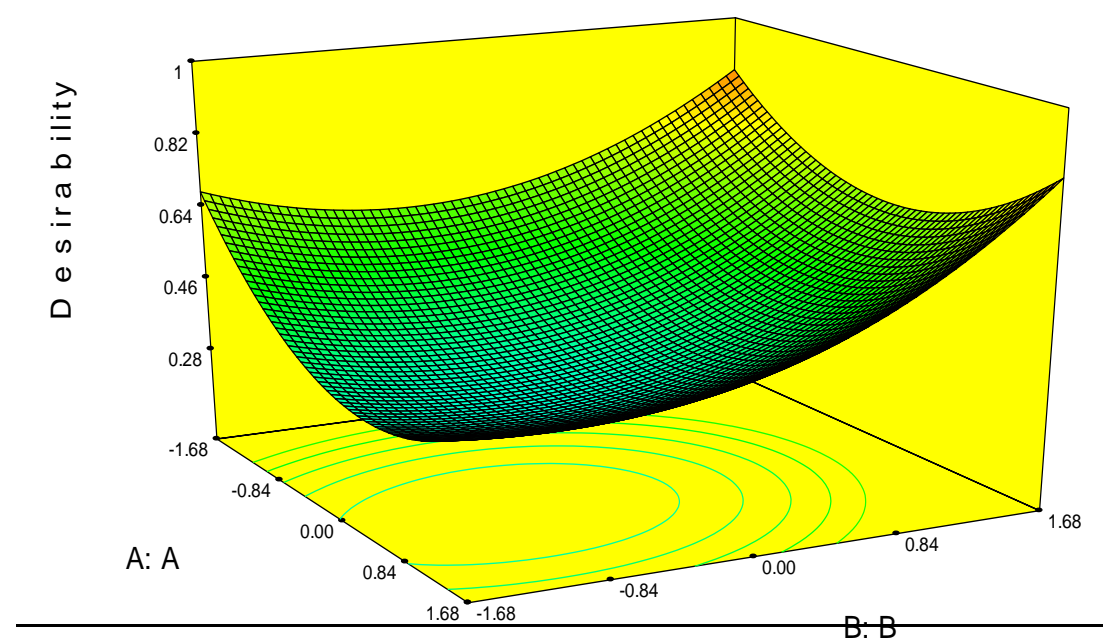

Figure 2. 3D Response Surface Plot for Desirability Function, Actual factor "C" at "-1.6818" level

\section{CONCLUSIONS}

The application of response surface methodology (RSM) for modeling and optimizing a manufacturing process was discussed. Central composite rotatable design was used to design an experimental plan for modeling the effects of three factors on two responses. A total of 40 experiments including center points were conducted. Results that obtained via designed experiments have entered software package design expert. Response functions were generated and coefficients were predicted by using experimental data. Finally the responses were optimized simultaneously thanks to desirability function. An overall desirability function value of 0,87 obtained. Optimization results were evaluated with company officials. Thanks to this project, company found a way to improve the quality of related products without incurring extra cost. The results show that RSM can be successfully applied to model and optimize real life problems. As future research, we suggest to apply RSM for modeling and optimization of other products of company simultaneously to improve overall product quality.

\section{REFERENCES}

1. A. Arun premnath, T. Alwarsamy, T. Abhinav and C. Adithya Krishnakant, Surface roughness prediction by response surface methodology in milling of hybrid aluminium composites, Procedia Engineering 38, 745 - 752, 2012.

2. A. I. Khuri, Response surface methodology and related topics, World Scientific Publishing Co. Pte. Ltd., 457, 2006.

3. C. H. Aladag and O. Köksoy, A tabu search meta-heuristic approach to the dual response systems problem, Expert Systems with Applications 38, 15370-15376, 2011. 
4. C. Jianjiang, X. Renbin and Z. Yifang, A response surface based hierarchical approach to multidisciplinary robust optimization design, International Journal of Advanced Manufacturing Technology 26(4), 301-309, 2005.

5. C. S. Aksezer, On the sensitivity of desirability functions for multiresponse optimization, Journal of Industrial and Management Optimization 4(4), 685-696, 2008

6. D. C. Montgomery and G. C. Runger, Applied statistics and probability for engineers, John Wiley \& Sons, Inc., 768 p, 2011.

7. G. Wang, G. Zhao, H. Li and Y. Guan, Research on optimization design of the heating-cooling channels for rapid heat cycle molding based on Response Surface Methodology and constrained particle swarm optimization, Expert Systems with Applications 38, 6705-6719, 2011.

8. I. Asiltürk and S. Neşeli, Multi response optimisation of CNC turning parameters via Taguchi method-based response surface analysis, Measurement 45, 785-794, 2012.

9. I. Ben-Gal and J. Bukchin, The ergonomic design of workstations using virtual manufacturing and response surface methodology, IIE Transactions 34, 375-391, 2002.

10. I. Kaymaz and C. A. McMahon, A response surface method based on weighted regression for structural reliability analysis, Probabilistic Engineering Mechanics 20(1), 11-17, 2005.

11. J. Lim, M. Kim, M. Kim, T. Oh, O. Kang, B. Min, A. S. Rao and C. Yoo, A systematic model calibration methodology based on multiple errors minimization method for the optimal parameter estimation of ASM1, Korean Journal of Chemical Engineering 29(3), 291-303, 2012.

12. L. Wu, K. Yick, S. Ng and J. Yip, Application of the Box-Behnken design to the optimization of process parameters in foam cup molding, Expert Systems with Applications 39, 8059-8065, 2012.

13. M. Gönen and E. Alpaydın, Regularizing multiple kernel learning using Response Surface Methodology, Pattern Recognition 44, 159-171, 2011.

14. O. Isik, An integrated probability-based approach for multiple response surface optimization, Phd. Thesis, Old Dominion University, 107 p, 2009.

15. P. L. Goethals, Modeling and optimization of stochastic process parameters in complex engineering systems, Phd. Thesis, Clemson University, 262 p, 2011.

16. P. P. Anderson, R. F. Joao and P. B. Pedro, A multivariate hybrid approach applied to AISI 52100 hardened steel turning optimization, Journal of Materials Processing Technology 189, 26-35, 2007.

17. S. Gopalakannan, T. Senthilvelan and S. Ranganathan, Modeling and Optimization of EDM Process Parameters on Machining of Al 7075-B4C MMC Using RSM, Procedia Engineering 38, 685 - 690, 2012.

18. U. Natarajan, PR. Periyanan and S. H. Yang, Multiple-response optimization for micro-endmilling process using response surface methodology, International Journal of Advanced Manufacturing 56, 177-185, 2011.

19. W. M. Carlyle, D. C. Montgomery and G. C. Runger, Optimization problems and methods in quality control and improvement, Journal of Quality Technology 32(1), $1-31,2000$. 